\title{
Escherichia coli and Staphylococcus aureus: bad news and good news from the European Antimicrobial Resistance Surveillance Network (EARS-Net, formerly EARSS), 2002 to 2009
}

C Gagliotti ${ }^{1}$, A Balode², F Baquero³, J Degener 4 , H Grundmann 5 , D Gür ${ }^{6}$, V Jarlier7, G Kahlmeter ${ }^{8}$, J Monen ${ }^{5}$, D L Monnet ${ }^{1}$,

G M Rossolini ${ }^{9}$, C Suetens ${ }^{1}$, K Weist ${ }^{1}$, 0 Heuer (ole.heuer@ecdc.europa.eu) ${ }^{1}$, the EARS-Net Participants (Disease Specific Contact Points for AMR) ${ }^{10}$

1. European Centre for Disease Prevention and Control (ECDC), Stockholm, Sweden

2. Paul Stradins Clinical University Hospital, Riga, Latvia

3. University Hospital Ramón y Cajal, Madrid, Spain

4. University Medical Centre Groningen, Groningen, the Netherlands

5. National Institute for Public Health and the Environment (RIVM), Bilthoven, the Netherlands

6. Hacettepe University School of Medicine, Ankara, Turkey

7. Pitié-Salpêtrière Hospital, Paris Cedex 13, France

8. Central Hospital Växjö, Växjö, Sweden

9. University of Siena, Siena, Italy

10. EARS-Net participant are listed at the end of the article

Citation style for this article:

Gagliotti C, Balode A, Baquero F, Degener J, Grundmann H, Gür D, Jarlier V, Kahlmeter G, Monen J, Monnet DL, Rossolini GM, Suetens C, Weist K, Heuer O, the EARSNet Participants (Disease Specific Contact Points for AMR). Escherichia coli and Staphylococcus aureus: bad news and good news from the European Antimicrobial Resistance Surveillance Network (EARS-Net, formerly EARSS), 2002 to 2009. Euro Surveill. 2011;16(11):pii=19819. Available online: http://www.eurosurveillance. org/ViewArticle.aspx?Articleld=19819

Based on data collected by the European Antimicrobial Resistance Surveillance Network (EARS-Net) and the former EARSS, the present study describes the trends in antimicrobial susceptibility patterns and occurrence of invasive infections caused by Escherichia coli and Staphylococcus aureus in the period from 2002 to 2009. Antimicrobial susceptibility results from 198 laboratories in 22 European countries reporting continuously on these two microorganisms during the entire study period were included in the analysis. The number of bloodstream infections caused by E. coli increased remarkably by $71 \%$ during the study period, while bloodstream infections caused by S. aureus increased by $34 \%$. At the same time, an alarming increase of antimicrobial resistance in E. coli was observed, whereas for $S$. aureus the proportion of meticillin resistant isolates decreased. The observed trend suggests an increasing burden of disease caused by $E$. coli. The reduction in the proportion of meticillinresistant S. aureus and the lesser increase in S. aureus infections, compared with $E$. coli, may reflect the success of infection control measures at hospital level in several European countries.

\section{Introduction}

Escherichia coli and Staphylococcus aureus are the main causes of bloodstream infections (BSIs) in humans. The antimicrobial resistance of $E$. coli causing BSI is increasing alarmingly across Europe, while meticillin-resistant S. aureus (MRSA) is decreasing in several countries [1]. The antimicrobial susceptibility of these microorganisms and other selected bacterial pathogens causing invasive infections has been monitored for a decade by the European Antimicrobial Resistance Surveillance System (EARSS) [1]. Coordination and administration of the EARSS project, previously conducted by the Dutch National Institute of Public Health and the Environment (RIVM), was transferred to the European Centre for Disease Prevention and Control (ECDC) on 1 January 2010, and the network was renamed European Antimicrobial Resistance Surveillance Network (EARSNet). The first data collection by EARS-Net (antimicrobial susceptibility data referring to 2009) took place during June and July 2010.

Whereas detailed analysis and trends at the national level are available in the EARSS and EARS-Net reports $[1,2]$, the present study describes the trends in susceptibility patterns and number of invasive infections caused by E. coli and S. aureus in Europe from 2002 to 2009 , based on data from laboratories reporting continuously during this period.

\section{Methods}

Data for E. coli and S. aureus BSIs were extracted from the EARSS/EARS-Net database for a convenience sample of laboratories reporting susceptibility results continuously during the period from 2002 to 2009 for aminopenicillin, fluoroquinolones, third generation cephalosporins and aminoglycosides in $E$. coli and for oxacillin in S. aureus [3]. Countries in which no laboratory participated for the entire period or that had only a small data set (less than 20 isolates per microorganism per year) were not included in the analysis. Only 
the first isolate per patient, microorganism and year was included as a representative sample. Sampling and processing of isolates was done in agreement with the EARSS manual 2005 [3]. Resistance ( $R$ category of $S, I, R$ ) was defined by the guidelines in use in the reporting countries.

The number of BSIs caused by $E$. coli and S. aureus and the proportions of third-generation cephalosporinresistant $E$. coli and of MRSA were recorded for each year from 2002 to 2009. To assess the patterns of combined resistance of $E$. coli, the following antimicrobial classes were analysed: aminopenicillins (ampicillin and amoxicillin), aminoglycosides (gentamicin, tobramycin and amikacin), third-generation cephalosporins (ceftriaxone, cefotaxime and ceftazidime) and fluoroquinolones (ciprofloxacin, ofloxacin and levofloxacin). Resistance to a class was defined as resistance ( $R$ category) to at least one agent in the class. The significance of the temporal linear trends for resistance proportions was evaluated by the Cochran-Armitage test for trend.

\section{Results}

A total of 198 laboratories in 22 countries continuously reported data from 2002 to 2009 . The number of laboratories per country ranged between one (Iceland and Malta) and 33 (Czech Republic), while the mean number of $E$. coli and $S$. aureus isolates reported yearly per country ranged from 96 to 1,973 and from 56 to 1,290 , respectively (Table).

Considering the whole group of selected laboratories, the reported number of $E$. coli BSIs increased by $71 \%$ from 10,688 in 2002 to 18,240 in 2009 (Figure 1); most of the rise ( $38 \%$ of $71 \%$ ) in E. coli BSIs was due to isolates resistant to two or more antimicrobials. During the same period, S. aureus BSIs showed a $34 \%$ increase from 7,855 to 10,503 (Figure 1). In the period from 2002 to 2009 , if only E.coli susceptible to aminopenicillins, third-generation cephalosporins, fluoroquinolones and aminoglycosides are considered, the number of BSIs increased by $39 \%$. Similarly, the BSIs caused by meticillin-susceptible $S$. aureus showed an increase of $37 \%$.

In the period from 2002 to 2009 , the proportion among all $E$. coli of $E$. coli resistant to third-generation cephalosporins increased significantly from $1.7 \%$ to $8 \%$ ( $p<0.001)$ and the proportion of MRSA decreased from $21.5 \%$ to $19.7 \%$ ( $p<0.001$ ) (Figure 2 ). Similar trends of resistance proportions as observed for aggregated data of all 198 laboratories were also observed at country level in 18 of 22 countries for E. coli, and in seven of 22 countries for $S$. aureus.

\section{TABLE}

Mean annual number of Escherichia coli and Staphylococcus aureus isolates per country reported by laboratories (n=198) reporting continuously to EARSS/EARS-Net, 2002-09

\begin{tabular}{|c|c|c|c|}
\hline \multirow{2}{*}{ Country } & \multirow{2}{*}{ Number of laboratories } & \multirow{2}{*}{$\begin{array}{c}\text { Number of Escherichia coli isolates } \\
\text { Mean per year (2002-09) }\end{array}$} & \multirow{2}{*}{$\begin{array}{c}\text { Number of Staphylococcus aureus isolates } \\
\text { Mean per year (2002-09) }\end{array}$} \\
\hline & & & \\
\hline Austria & 10 & 802 & 630 \\
\hline Belgium & 9 & 646 & 343 \\
\hline Bulgaria & 7 & 96 & 82 \\
\hline Czech Republic & 33 & 1,837 & 1,290 \\
\hline Estonia & 5 & 142 & 125 \\
\hline Finland & 5 & 849 & 381 \\
\hline France & 12 & 1,583 & 1,018 \\
\hline Germany & 2 & 156 & 121 \\
\hline Greece & 22 & 829 & 472 \\
\hline Hungary & 14 & 446 & 526 \\
\hline Iceland & 1 & 97 & 56 \\
\hline Ireland & 15 & 1,086 & 961 \\
\hline Italy & 3 & 237 & 166 \\
\hline Luxembourg & 4 & 176 & 80 \\
\hline Malta & 1 & 104 & 96 \\
\hline Netherlands & 4 & 291 & 238 \\
\hline Norway & 7 & 975 & 467 \\
\hline Portugal & 8 & 559 & 574 \\
\hline Slovenia & 9 & 572 & 321 \\
\hline Spain & 19 & 1,973 & 835 \\
\hline Sweden & 3 & 578 & 331 \\
\hline United Kingdom & 5 & 641 & 373 \\
\hline
\end{tabular}

EARSS: European Antimicrobial Resistance Surveillance System; EARS-Net: European Antimicrobial Resistance Surveillance Network. 
Combined resistance in $E$. coli (defined as resistance to two, three or four antimicrobial classes reported to EARS-Net) showed a significant increase ( $p<0.001)$ (Figure 3) whereas single resistance diminished from $37.1 \%$ in 2002 to $35.8 \%$ in 2009 ( $p<0.001$ ). The proportion of $E$. coli isolates susceptible to all four antimicrobial classes decreased from $51.4 \%$ in 2002 to $41.7 \%$ in 2009 (p<0.001).

\section{Discussion}

The increase in antimicrobial resistance in $E$. coli between 2002 and 2009 was evident both in the observed increase of combined resistance and in the reduction of full susceptibility to the antimicrobials included in the analysis. In the same time period

\section{FIGURE 1}

Annual number of bloodstream infections caused by Escherichia coli and Staphylococcus aureus, EARSS/EARSNet, 2002-09 (22 countries/198 laboratories)

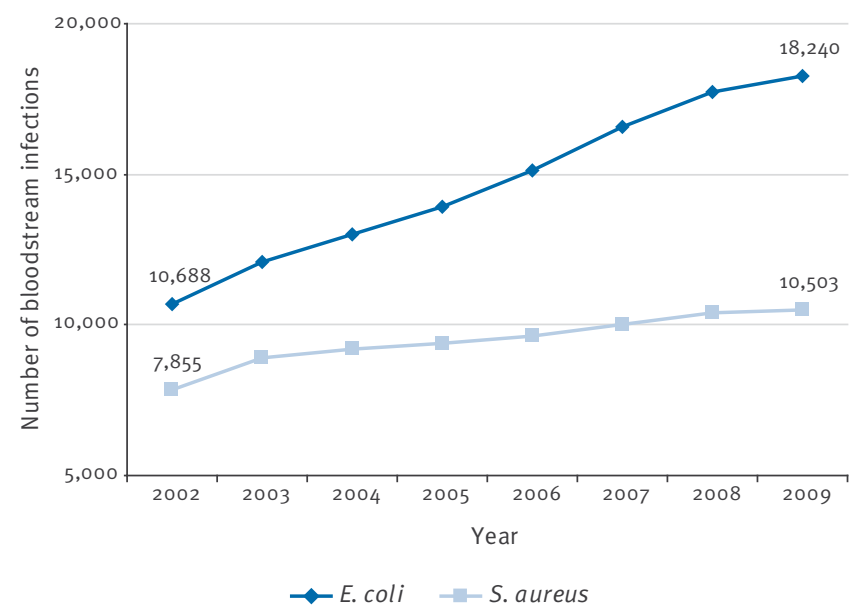

EARSS: European Antimicrobial Resistance Surveillance System; EARS-Net: European Antimicrobial Resistance Surveillance Network.

\section{FIGURE 2}

Proportion of third-generation cephalosporin-resistant Escherichia coli and of meticillin-resistant Staphylococcus aureus, EARSS/EARS-Net, 2002-09 (22 countries/198 laboratories)

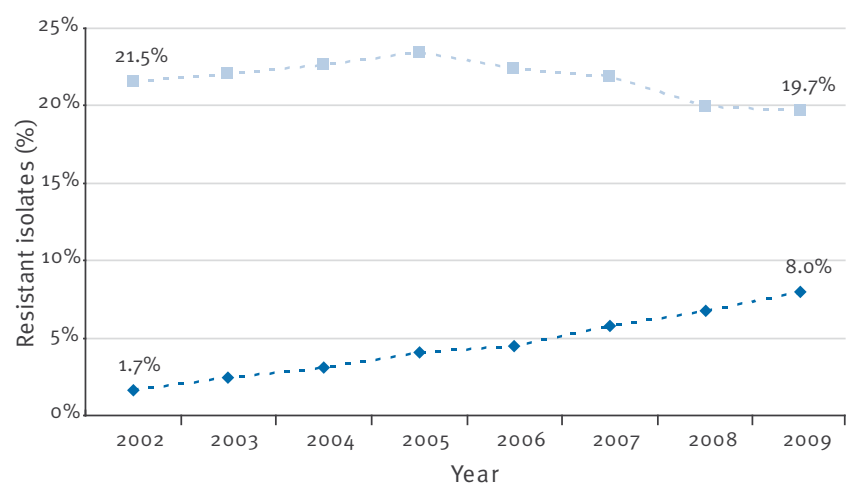

- Third-generation cephalosporin-resistant E. coli among total E. coli - MRSA a mong total S. aureus

EARS-Net: European Antimicrobial Resistance Surveillance Network; EARSS: European Antimicrobial Resistance Surveillance System. and considering the same data source, a significant decrease of meticillin resistance was observed for S. aureus. For this species, the number of BSIs increased less $(+34 \%)$ than for $E$. coli BSI $(+71 \%)$. Consistently, increasing resistance in $E$. coli and combined resistance of invasive and non-invasive isolates was reported by several European countries [4-8]. At the same time, the proportion of MRSA showed a significant decrease in many European countries [1,2]. The numbers of BSIs caused by MRSA, as reported by the mandatory surveillance system in England, decreased by $56 \%$ between 2004 and 2008 [9], and in France a significant decrease in the occurrence of MRSA was reported in 2008 [10]. A similar reduction in the rate of healthcare-associated invasive MRSA infections was observed in the general population in the United States [11].

The sampling approach selected for this study is likely to eliminate a large part of the possible temporal variation in the size of the catchment population behind the numbers. Based on the available surveillance data, it provides the best possible evidence of the increasing burden of disease caused by $E$. coli and $S$. aureus bacteraemia in the European Union. Nevertheless, if the population covered by the participating laboratories became larger during the study period, this may have contributed to the observed increase. Likewise, the sample approach includes laboratories without taking into account the size of the country, and therefore does not allow detailed analysis at national level. The disparity in the BSI trends for E. coli and S. aureus could partly be explained by ascertainment bias leading to higher reporting of $E$. coli infections. This could be caused by an increase of empirical treatment failures triggering delayed diagnostic procedures (blood culture). A similar upward trend in the number of reported cases of $E$. coli BSIs has been observed by

\section{FIGURE 3}

Combined resistance of Escherichia coli to aminopenicillins, third-generation cephalosporins, fluoroquinolones and aminoglycosides, EARSS/EARS-Net, 2002-09 (22 countries/198 laboratories)

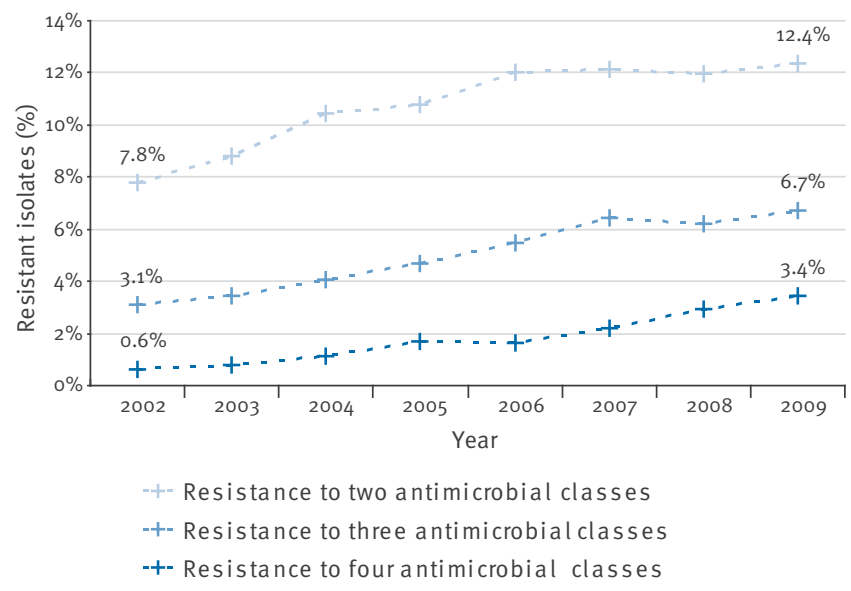

EARSS/EARS-Net: European Antimicrobial Resistance Surveillance Network; EARSS: European Antimicrobial Resistance Surveillance System. 
the national voluntary surveillance scheme in England, Wales, and Northern Ireland between 2005 and 2009. The increase (37\%) in BSIs caused by E. coli observed by this surveillance system is larger than the increase in all BSIs reported during that time period [12].

Despite the study limitations, the observed trends regarding resistance to third-generation cephalosporins and combined resistance in $E$. coli deserve further consideration. According to the results, it appears that the emergence and spread of combined resistance during the study period was the main factor that influences the decline in antimicrobial susceptibility in E. coli. From 2002 to 2009, a relative increase of combined resistance with a concurrent reduction of the proportion of single resistance was observed. The resistance pattern with the largest relative growth in the period from 2002 to 2009 was resistance to all four antimicrobial classes under surveillance: the frequency of this pattern increased more than fivefold from $0.6 \%$ to $3.4 \%$. This trend suggests that within the subpopulation of resistant isolates, there was a continuous relative growth of combined resistance, possibly caused by the addition of resistance traits to strains that were already resistant to at least one of the considered antimicrobial classes. This trend may be explained by the spread of multidrug-resistant plasmids which also contain genes for the extended-spectrum beta-lactamase (ESBL) production [13-16].

Resistance trends were monitored using interpretations: susceptible, intermediate or resistant (SIR) [3], since the actual minimum inhibitory concentrations (MIC) were not systematically available from participating laboratories. Reporting MICs rather than SIR interpretations based on clinical breakpoints would improve the dynamic monitoring of subtle, incremental changes in antimicrobial susceptibility. Moreover, the interpretation using SIR categories reported to EARSNet is based on breakpoints defined in the participating countries' guidelines over time. Nevertheless, for the combinations of microorganisms and antimicrobials included in this study, the variation in the proportion of resistance caused by using different guidelines is very limited (unpublished data).

\section{Conclusion}

This is a serious concern since, if the increasing trend of antimicrobial resistance and the spread of ESBL are not contained, the use of carbapenems will increase favouring the emergence of carbapenemase producing enterobacteria. This has been already observed for Klebsiealla pneumoniae in Greece, Israel and Cyprus $[1,2]$.

At the same time, S. aureus showed a relatively smaller increase in the number of reported BSIs, but a significant decrease in the proportion of MRSA overall in the countries participating in EARSS/EARS-Net. This could be the result of public health efforts targeted at the containment of MRSA in several European countries.*
Although an overall decreasing trend for MRSA is evident in Europe, not all countries contribute to this result. Efforts to reduce the occurrence of MRSA should remain a priority irrespective of decreasing trends.

In this context, coordinated international surveillance is particularly important in order to obtain accurate knowledge of the occurrence and spread of antimicrobial resistance and to plan public health interventions.

* Authors' correction:

At the request of the authors, the following correction was made on 18 March 2011: The sentence 'This could be the result of public health efforts targeted at the containment of MRSA in several European countries and in the United States.' was changed to 'This could be the result of public health efforts targeted at the containment of MRSA in several European countries.'

\section{Acknowledgements}

The authors acknowledge the work performed by the staff at the national laboratories providing data for EARSS/EARSNet, and Dr John Stelling for guiding and supporting the WHONET users among the data managers at country level.

EARS-Net Participants (Disease Specific Contact Points for AMR): Austria: P Apfalter, G El Belazi, G Fluch, C Hain, H Hrabcik, W Koller, S Metz-Gercek, R Muchl, R Strauss; Belgium: B Catry, M Fauville Dufaux, H Goossens, M Goossens, L Meulenbergs, S Vaerenberg; Bulgaria: T Kantardjiev, B Markova, J Stoyanova Marteva-Proevska; Cyprus: P Maikanti Charalambous, D Pieridou Bagatzouni; Czech Republic: V Jakubu, P Urbaskova, H Zemlickova; Denmark: M Galle, A Hammerum, S Olsen, K Schultz Nielsen, R Skov; Estonia: T Aro, I Dontsenko, M Ivanova, K Kermes, A Lemetsar; Finland: A Hakanen, 0 Lyytikäinen, T Möttönen; France: B Coignard, H De Valk, S Maugat, D Trystram; Germany: D Altmann, A Gilsdorf, I Noll, A Tille, W Witte; Greece: V Miriagou, M Polemis, A Tsakris, A Vatopoulos; Hungary: K Böröcz, M Melles, Á Tóth, Z Vegh; Iceland: H Briem, L Helgadottir, K Kristinsson; Ireland: J Brazil, R Cunney, M Fitzgerald, P Hanrahan, S Murchan, O Murphy, B O’Connell; Italy: F D’Ancona, S Iannazzo, A Pantosti; Latvia: R Nikiforova; Lithuania: A Berzanskyte, L Dagyte-Sileikiene, J Miciuleviciene; Luxembourg: D Hansen-Koenig, M Perrin-Weniger; Malta: M Borg, E Scicluna, R Zammit Cassar; Netherlands: A De Neeling, N Van De Sande; Norway: K Konsmo, GS Simonsen, M Steinbakk, K Wathne, F Width Gran; Poland: W Hryniewicz, M Sitkiewicz, M Sulik, D Zabicka; Portugal: M Caniça, C Costa, V Manageiro; Romania: I Codita, R Serban; Slovenia: N Bergant, J Kolman, M Mueller-Premru; Spain: J Campos Marques, J Oteo Iglesias, M Perez-Vazquez; Sweden: I Alefjord, A Linde, B Olsson-Liljequist, J Struwe; United Kingdom: R Blackburn, K Eastick, G Edwards, I Fisher, R Hill, A Johnson, F Johnston, G Mcilvenny, A Mullings, N Nirmal, L Patterson, J Wilson.

\section{References}

1. Rijksinstituut voor Volksgezondheid en Milieu (RIVM). EARSS annual report 2008: Bilthoven; RIVM; 2009. Available from: http://www.ecdc.europa.eu/en/activities/surveillance/EARSNet/Documents/2008_EARSS_Annual_Report.pdf

2. European Centre for Disease Prevention and Control (ECDC). Antimicrobial resistance surveillance in Europe 2009. Annual Report of the European Antimicrobial Resistance Surveillance Network (EARS-Net): Stockholm: ECDC; 2010. Available from:http://ecdc.europa.eu/en/publications/ Publications/1011_SUR_annual_EARS_Net_2009.pdf

3. Rijksinstituut voor Volksgezondheid en Milieu (RIVM). EARSS manual 2005: Bilthoven: RIVM; 2005. Available from: http:// www.ecdc.europa.eu/en/activities/surveillance/EARS-Net/ Documents/EARS-Net-Microbiological-manual.pdf

4. DANMAP 2009. Use of antimicrobial agents and occurrence of antimicrobial resistance in bacteria from food animals, foods and humans in Denmark: Copenhagen: Danish Veterinary Institute, Danish Veterinary and Food Administration, Statens Serum Institut, Danish Medicines Agency, National Food Institute, Technical University of Denmark; Sep 2010. ISSN: 1600-2032. Available from: http://www.danmap.org/pdfFiles/ Danmap_2009.pdf 
5. Health Protection Agency (HPA). Antimicrobial Resistance and Prescribing in England, Wales and Northern Ireland, 2008: London: HPA; Jul 2008. Available from: http://www.hpa.org uk/web/HPAwebFile/HPAweb_C/1216798080469

6. NORM/NORM-VET 2009. Usage of Antimicrobial Agents and Occurrence of Antimicrobial Resistance in Norway. Troms $\varnothing /$ Oslo: NORM-VET; 2010. ISSN: 1502-2307. Available from: http://www.unn.no/getfile.php/UNN-Internett/Fagfolk/www. antibiotikaresistens.no/NORM-09/NORM_VET_2009.pdf

7. Rijksinstituut voor Volksgezondheid en Milieu (RIVM). NethMap 2009. Consumption of antimicrobial agents and antimicrobial resistance among medically important bacteria in the Netherlands: Amsterdam: Dutch Foundation of the Working Party on Antibiotic Policy (SWAB); 2009. Available from: http:// www.swab.nl/swab/cms3.nsf/uploads/1D61A8F6E60555F3C125 763900414B7B/\$FILE/nethmap2009_21-9-2009.pdf

8. SWEDRES 2009. A Report on Swedish Antimicrobial Utilisation and Resistance in Human Medicine. Swedish Strategic Programme against Antibiotic Resistance (STRAMA). Swedish Institute for Infectious Disease Control: Stockholm; 2010. Available from: http://www.strama.se/uploads/docs/ Swedres\%202009\%20final\%20version.pdf

9. Pearson A, Chronias A, Murray M. Voluntary and mandatory surveillance for methicillin-resistant Staphylococcus aureus (MRSA) and methicillin-susceptible S. aureus (MSSA) bacteraemia in England. J Antimicrob Chemother. 2009;64 Suppl 1:i11-7.

10. Anonymous. Recent trends in antimicrobial resistance among Streptococcus pneumoniae and Staphylococcus aureus isolates: the French experience. Euro Surveill. 2008;13(46): pii=19035. Available from: http://www.eurosurveillance.org/ ViewArticle.aspx?Articleld=19035

11. Kallen AJ, Mu Y, Bulens S, Reingold A, Petit S, Gershman K, et al. Health care-associated invasive MRSA infections, 20052008. JAMA. 2010;304(6):641-8

12. Health Protection Agency (HPA). Escherichia coli bacteraemia in England, Wales, and Northern Ireland, 2005 to 2009: London: HPA; 14 Apr 2010. Available from: http://www.hpa. org.uk/web/HPAwebFile/HPAweb_C/1274087560639

13. Arpin C, Quentin C, Grobost F, Cambau E, Robert J, Dubois V, et al. Nationwide survey of extended-spectrum \{beta\}-lactamaseproducing Enterobacteriaceae in the French community setting. J Antimicrob Chemother. 2009;63(6):1205-14.

14. Coque TM, Baquero F, Canton R. Increasing prevalence of ESBL-producing Enterobacteriaceae in Europe. Euro Surveill. 2008 Nov 20;13(47):pii=19044. Available from: http://www. eurosurveillance.org/ViewArticle.aspx?Articleld=19044

15. Livermore DM, Canton R, Gniadkowski M, Nordmann P, Rossolini GM, Arlet G et al. CTX-M: changing the face of ESBLs in Europe. J Antimicrob Chemother. 2007;59(2):165-74.

16. Potz NA, Hope R, Warner M, Johnson AP, Livermore DM; London \& South East ESBL Project Group. Prevalence and mechanisms of cephalosporin resistance in Enterobacteriaceae in London and South-East England. J Antimicrob Chemother. 2006;58(2):320-6. 